\title{
Tornando Visível a Arte Contemporânea ${ }^{1}$
}

\author{
Eduardo Coimbra² e Ricardo Basbaum ${ }^{3}$
}

Em uma seqüência de artigos, publicados inicialmente no suplemento Idéias do Jornal do Brasil, e agora reunidos no livro Argumentação Contra a Morte da Arte, o crítico de arte Ferreira Gullar levantou diversos impedimentos acerca da legitimidade da arte contemporânea. Por uma série de dificuldades, esta produção de arte nem sempre tem sido trazida a público de modo claro e preciso, sendo freqüentemente questionada em termos do seu próprio valor e possibilidade. Como artistas plásticos, produtores e pensadores de arte, achamos necessário expressar nossas posições acerca dessas questões, deslocando-as de um horizonte anacrônico, limitado e preconceituoso - de onde partem visões como as de Gullar - para um campo ampliado, atual, crítico e transformador.

Grande parte dessa visão que coloca em dúvida a legitimidade da produção contemporânea deve-se, na realidade, à precariedade do meio de arte no Brasil: crítica que não cria pensamento em contato com as obras; mercado que não promove a circulação dos trabalhos; museus sem capacidade de formação de acervos.

Pode-se dizer que o papel da crítica foi fundamental para a articulação e eclosão do movimento Neoconcreto, momento raro em que crítica e produção caminharam juntas. Todas as possibilidades que se seguiram, experimentadas pela arte dos anos 60, no Brasil, têm origem na consistência e sofisticação deste embate: idéias e conceitos, em arte, são sempre formados verbal e plasticamente, de modo que não é possível existir

\footnotetext{
1 Texto publicado originalmente em Ato All - Exposição de Arte Contemporânea, Goiânia, UFGO: Instituto de Artes, 1995. Catálogo. Incluído na coletânea Arte Contemporânea Brasileira - texturas, dicções, ficções, estratégias, Org. Ricardo Basbaum, Rio de Janeiro: Contra Capa, 2001. Republicado em Ricardo Basbaum, Manual do artista-etc, Rio de Janeiro: Azougue, 2013.

2 Eduardo Coimbra é formado em engenharia pela PUC-Rio, começou sua carreira artística no início dos anos 90. A partir do final da década de 90 seu trabalho se concentrou em proposições espaciais, com pesquisas nas relações entre arte, arquitetura e paisagem.

3 Ricardo Basbaum é Professor Visitante da Universidade de Chicago (2013), Artista Residente da Audain Gallery (Vancouver, 2014), Professor do Departamento de Arte da Universidade Federal Fluminense e autor de Manual do artista-etc (Azougue, 2013). Participa regularmente de exposições e projetos desde 1981, dentre elas, documenta 12 (2007), 35 ${ }^{\circ}$ Panorama da Arte Brasileira (Museu de Arte Moderna de São Paulo, 2017), 20 a Bienal de Sydney (2016) e The School of Kiev - Bienal de Kiev (The House of Clothes, Kiev, 2015).
} 
criação crítica desvinculada de um contato direto com as obras, assim como é ingênuo supor que se pode produzir arte sem pensamento. O Suplemento Dominical, do Jornal do Brasil, foi um espaço, na imprensa, que permitiu o desenvolvimento de uma discussão deste tipo.

A crítica de arte, por diversos fatores, não manteve a continuidade dessa linha de atuação, seguindo um desempenho pontuado por espasmos isolados e desarticulados entre si, de criação de pensamento, em meio a momentos de retração crítica. Nesse sentido, um último momento brilhante da relação crítica-obra ocorreu em um segmento da produção brasileira dos anos 70, articulado por veículos como Malasartes, Opinião, Espaço ABC e, posteriormente, A Parte do Fogo.

Já os anos 80 foram marcados por um falso antagonismo entre crítica e pintura, nefasto para ambas, anulando o espaço de atuação da crítica, suplantada pelos valores de mercado, e restringindo a pintura ao prazer de pintar. Para os ideólogos da Geração 80, a pintura seria "independente do discurso verbal da crítica", numa postura que reduz o objeto artístico a uma condição passiva, contemplativa e esteticista. Esta postura redutora enraizou-se de tal modo no circuito de arte (do Rio de Janeiro), que contaminou não só a crítica como também museus e mercado, incapacitando-os de localizar corretamente os segmentos atuantes da produção contemporânea. $\mathrm{Na}$ realidade, essa passividade traz implícita uma conceituação do artista como um subprodutor, do qual se espera que produza de acordo com expectativas já delineadas por um circuito que não aceita ser questionado e transformado pela atividade artística, e onde as vozes da crítica - dispensadas pela imprensa ou ocupadas em reuniões institucionais - resumem-se, quando muito, a três minutos de bate-papo no calor do vernissage.

Para tornar visível a produção contemporânea é necessário o emprego de métodos corretos, de modo a extrair de um conjunto de atividades caóticas e disformes os contornos precisos de um acontecimento artístico. A dificuldade desse trabalho é a exigência de estar sempre disponível para recriar parâmetros críticos, reconhecendo a primazia das obras na deflagração desse processo; do contrário, uma reflexão calcada em pré-conceitos tornar-se-ia uma especulação estética vazia e estéril.

Nos últimos trinta anos, as pesquisas plásticas, avançando além da arte moderna, nada mais fizeram do que radicalizar e aprofundar diversas questões, entre as quais, romper com a ideia da especialização do artista em um meio específico - busca da essência -, 
combater a discriminação entre materiais e meios artísticos e não-artísticos, e ampliar o campo de atuação da arte para além de um espaço próprio, fechado, que não se relacionasse com outros campos do conhecimento.

Produzir arte hoje é operar com vetores de um campo ampliado. Um campo que se abre ao entrecruzamento das diversas áreas do conhecimento, num panorama transdisciplinar, sem prejuízo de sua autonomia e especificidade enquanto prática da visualidade. A cultura como paisagem não-natural, configura o território onde se move o artista: sua ação transforma-se numa intervenção precisa ao mobilizar instabilidades do campo cultural (regiões da cultura que permitem problematizações, conflitos, paradoxos), por meio de uma inteligência plástica que torna visível uma rede de relações entre múltiplos pontos de oposições, onde o trabalho de arte é um dispositivo de processamento simultâneo e ininterrupto, e nunca uma representação, destas relações.

Para resgatar a importância da produção artística contemporânea, como valor cultural, é necessário aceitar e compreender, repetimos, a primazia da obra, mas enquanto objeto especial de visibilidade através do qual propagam-se as questões instauradoras da trama do real - processo complexo, de compromisso ético-estético -, permitindo acesso a um veloz impulso de atualização. É a partir das obras que destacamos alguns pontos de oposição que atravessam a produção contemporânea como um todo, variando em maior ou menor grau, em suas diversas vertentes: (Esta pequena amostragem não menciona, por questão d espaço, muitos dos principais artistas contemporâneos)

TEXTO X IMAGEM - qualquer trabalho de arte se relaciona com o campo discursivo, mas alguns incorporam diretamente o texto como matéria ou narrativa imagética, em uma interpenetração entre verbal e plástico (Ed Ruscha, Joseph Kosuth, Barbara Kruger, John Baldessari, Rosângela Rennó, Jenny Holzer, Alex Hamburger, Leonilson).

COMUNICAÇÃO X PENSAMENTO - quando a instantaneidade comunicativa comprime o tempo de reflexão, com a utilização de logomarcas, sinais, diagramas, slogans (Matt Mullican, Ricardo Basbaum, Peter Halley, Lothar Baumgarten, Hans Haacke, Barbara Kruger). 
ESPAÇO ÍNTIMO X ESPAÇO PÚBLICO - qual a fronteira entre impessoal/público e íntimo individual? Anomalias da intimidade tornada pública, inocência, perversidade, desejo, obsessão, vida e morte (Robert Gober, Mike Kelly, Lia Menna Barreto, Matthew Barney, Ivens Machado, Fernanda Gomes, Rodrigo Cardoso, Tunga, Valeska Soares), o isolamento e massificação do indivíduo no espaço público e político (Jenny Holzer, Sandra Kogut, Andres Serrano, Cildo Meireles, Barrio, Gran Fury, Guerrilla Girls).

TECNOLÓGICO X TRANSLÓGICO - o disfuncionamento do objeto a partir de racionalidades não-lineares, e sua recuperação através de práticas apropriativas e de intervenção (Waltercio Caldas, Bertrand Lavier, Ange Leccia, Jac Leirner, Barrão, Ashley Bickerton, Eduardo Coimbra, Milton Machado, Mark Dion), e a desnaturalização do espaço ambiental e sua reconstrução por meio de uma neutralidade ativa e estrutural (Jan Vercruysse, Ana Tavares, John Armleder, Waltércio Caldas, Marcos Chaves, Carla Guagliardi).

REAL X SIMULAÇÃO - a persistência da imagem como fator de desmaterialização do Real, tornado signo, e também de criação de realidades virtuais onde, por um lado, a matéria está presente como adjetivo da imagem (Richard Artschwager, Leda Catunda, Haim Steinbach, João Modé, Márcia X., Brígida Baltar, Sérgio Romagnolo), e, por outro, a utilização de uma iconografia própria da reprodutibilidade, simultaneamente cópia e original, configura um território autocentrado que se remete sempre a si mesmo (Jeff Koons, Cindy Sherman, Allan McCollum, Haim Steinbach, Sherrie Levine, Márcia Ramos, William Wegman).

HISTÓRIA DA ARTE COMO UM CAMPO DA CULTURA - é possível encontrar trabalhos que questionam a possibilidade e a eficiência dos meios tradicionais (natureza da pintura e da escultura), através de procedimentos de extração ou saturação que tensionam seus limites enquanto meios específicos (Robert Ryman, Jorge Guinle, Anselm Kieffer, Daniel Senise, Julian Schnabel, Beatriz Milhazes, Marcus André, Alexandre Dacosta, Nuno Ramos, Frida Baranek, Carla Guagliardi, Ernesto Neto, José Resende, Angelo Venosa).

Todas essas oposições, e muitas outras que poderiam ser levantadas, configuram, na realidade, um conjunto de possibilidades na rede de relações que emergem de cada trabalho de arte, de modo que cada obra seja verdadeiramente atravessada por uma multiplicidade, e não por um só par de oposições. O mapeamento proposto acima deve 
ser entendido como uma das possíveis estratégias de localização e nunca como redução dessas obras a uma única questão. O trabalho é sempre anterior, ele é uma síntese plástica e não uma transcrição visual, constituindo-se como singularidade a partir do encontro sujeito-matéria-contexto. A afirmação de um campo propriamente plástico se conclui com o estabelecimento de novas modalidades de espaço e tempo, através das particularidades de cada obra, determinadas pela rede de relações que a constitui.

É importante lembrar que, dentro da perspectiva do campo ampliado, a relação destas obras com a História da Arte se dá principalmente a partir de um questionamento da natureza da obra de arte, e não tanto da natureza de cada meio de expressão. O artista contemporâneo é um operador da visualidade e seu trabalho uma intervenção no campo da cultura: é na atuação de uma inteligência plástica potencializada ao máximo que o artista vai buscar eficiência em sua prática, agora estruturada na forma de um Projeto Plástico, sob o signo da Transdisciplinaridade (cruzamento e superposição de vários campos do conhecimento) e Intermídia (livre trânsito entre diferentes meios de expressão, com a utilização de diversos materiais).

A partir das ideias expostas acima, demonstramos, em linhas gerais, ser possível construir um pensamento que permita discutir a produção contemporânea. Este texto se coloca como uma estratégia de pensamento gerada em confronto direto com as obras - compartilhando, simultaneamente, de um mesmo fluxo criativo -, devendo ser lido, portanto, junto com os trabalhos a que se refere. Só foi possível concretizá-lo a partir de conversas e discussões realizadas nos últimos três anos, no Rio de Janeiro, dentro do grupo VISORAMA 4 , formado por artistas plásticos identificados com as possibilidades da arte sob a perspectiva de um campo ampliado. Este esforço é necessário, para criar condições de compreensão de nossos próprios trabalhos, confrontando-os com as principais produções e questões da contemporaneidade, a nível nacional e internacional.

\footnotetext{
4 Grupo criado em 1990, por artistas que então residiam no Rio de Janeiro. Compunham o grupo inicialmente Carla Guagliardi, Eduardo Coimbra, João Modé, Márcia Ramos, Marcus André, Ricardo Basbaum, Rodrigo Cardoso, Rosângela Rennó e Valeska Soares, aos quais juntaram-se posteriormente Analu Cunha e Brígida Baltar. O Visorama produziu e organizou ciclos de debates no Rio de Janeiro e São Paulo e os simpósios "Visorama na UFRJ" e "Visorama na Documenta" (ambos em 1992).
} 